\title{
ENGINEERING EVALUATION OF RUPTURED STRAINER IN BUILDING 309
}

\author{
SEP 071833 \\ O STI
}

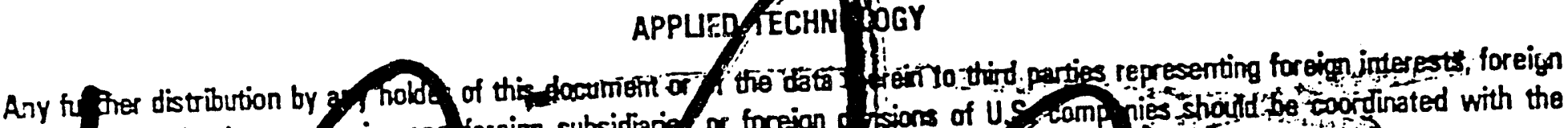
goven nents foreign cop panies and foreign subsidiarie or foreign d Direct r. Office of fice der Technolog Projects, U.S, Separtment of

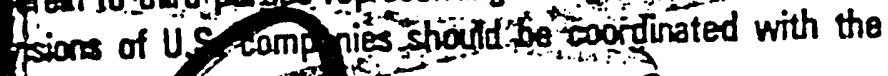
This ocument co of, since it is transmi hergy.

manc of work onder contracts with the

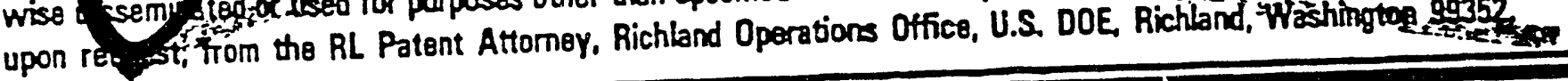

\section{Hanford Engineering Development Laboratory
J.N. Papenfuss
October 1982 \\ Hanford Engineering Development Laboratory
J.N. Papenfuss
October 1982 \\ Hanford Engineering Development Laboratory
J.N. Papenfuss
October 1982}

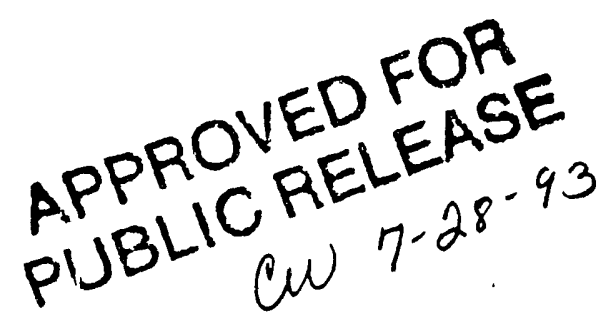

ins

made avate

onfider solely for 


\title{
ENGINEERING EVALUATION OF RUPTURED. STRAINER IN BUILDING 309 Prepared by \\ J. N. Papenfuss \\ October 1982 \\ LABORATORY SYSTEMS ENGINEERING
}

\begin{abstract}
DISCLAIMER
This report was prepared as an account of work sponsored by an agency of the United States Government. Neither the United States Gevernment nor any agency thereof, nor any of their employees, makes any warranty, express or implied, or assumes any legal liability or responsibility for the accuracy, completeness, or usefulness of any information, apparatus, product, or process disclosed, or represents that its use would not infringe privately cisned rights. Reference herein to any specific commercial product, prosess, or service by trade name, trademark, manufacturer, or otherwise does not necessarily constitute or imply its endorsement, recommendation, or favoring by the United States Government or any agency thereof. The views and opinions of authors expressed herein do not necessarily state or reflect those $a_{i}^{*}$ the United States Government or any agency thereof.
\end{abstract}


This report deals with the consequences of the ruptured steam strainer and is divided in two sections.

\section{SECTION 1}

This sections evaluates the engineering aspects of the ruptured steam strainer, investigates the events that culminated in the damage and considers factors that may have contributed to the incident.

Recommendations are presented to upgrade the system in Building 309 by incorporating hardware changes and proposes a change in operating procedures.

\section{SECTION 2}

This section utilizes the findings presented in Section 1 as a basis for conducting a review on the remainder of the 300 Area steam system, in order to identify similar problem areas.

Corrective action recommendations to reduce the risk of repeating component ruptures from water hammer conditions were developed out of the survey and the associated review. 


\section{SECTION 1}

\section{$1.0 \quad$ INTROOUCTION}

The following engineering evaluation was performed to find the underlying causes of the pressure boundary rupture in Building 309. It is important to identify the causes before establishing the guide lines to conjuct a comprehensive review of the 300 Area steam supply system. This evaluation investigates a system configuration that may lead to similar types of ruptures.

An incident similar to the strainer rupture occurred during 1979 in the steam system for Building 306, see Appendix-C for the engineering evaluation of this incident. In this incident "water hammer"* ruptured a valve bonnet during warm up. Incorporation of recommendations made in the foregoing report could have averted the strainer rupture in Building 309 . There was another incident during 1976 when the 12" diameter - West Export Main service steam outside building 384 was damaged by severe water hammer.

\subsection{SUMMARY}

The evaluation found that the strainer was ruptured during normal warm up to restore steam service for operational checkout of the recentiy-installed preheat coil. No signs of impending component failure could be found, rupturing was the first indication of the problem. Furthermore, this system has been placed in operation each year for several years by going through a warm up cycle prior to the incident, without any recorded problems.

Subsequent to the rupture incident, an investigation revealed a system and operating procedures with several anomalies, some of them sufficient to cause the rupture. The most severe stresses possible in a steam system are those which occur during warm up, if severe water hammer is present. This

*See "Water hammer narrative" page 10. 
can be seen from the damage that occurred during warm up from the following incidents: Bldg. $309-1982$, B1dg. 306 - 1979, and B1dg. 384 - West Export steam - 1976.

\subsection{CONCLUSION}

Rupturing of the strainer was due to severe water hammer subjecting a vulnerable component to loads well beyond the normal working pressures.

The strainer was rendered vulnerable for the following reasons:

- no engineered features to facilitate system warm up, i.e., a small size warm up bypass valve was not installed across the main steam isolating valve.

- incorrect steam main pipe slope - steam flow is opposite to pipe slope, trapping condensate with no means of draining. This reservoir then becomes a source of water slugs for water hammer.

- isolation valve is oversized - an 6" diameter $(50,000 \mathrm{lbs} / \mathrm{hr})$ valve serving a $2,500 \mathrm{lbs} / \mathrm{hr}$ system.

- a system that increases the velocity of steam as it flows through reducing pipe diameters (with a slug of water that remains at constant volume thereby increasing the force of impact from water hammer).

- a system configuration that cannot efficiently drain the condensate during warm up.

- a system configuration that concentrates the impact of the water slugs into the area of a component that is the most vulnerable to high pressures.

Opening the main steam isolating valve under existing operating procedures aggrevated the situation because:

- Turning the hand-wheel one revolution (or $2.8 \%$ of the total lift) is more than the system's warm up requirements, it takes 35 turns to open the valve $100 \%$.

- Water hammer cannot be detected in time to prevent an incident if only one operator performs all the work. 


\subsection{RECOMMENDATIONS}

Administrative directives, design changes, operating procedure changes, and nondestructive examination are required to reduce the risk of another rupture of the pressure boundary, and thus the corresponding risks of personnel injury or property damage. Details for each group of recommendations is as follows:

- Administrative Directive - Room $\# 8$ in Building 309 shall not be used as office space.

- Design Changes

Install a $1 / 2^{\prime \prime}$ diameter warm up bypass valve around the main steam isolating valve.

Increase the size of condensate collection leg - the volume of the present 4" diameter collection leg is approximately 0.036 cubic feet instead of the optimum 0.24 cubic feet - see figure 8 (Appendix A).

Reinstall the ruptured strainer replacement in the horizontal pipe beyond the influence of the elbow.

- Operating Procedure Changes

Replace present verbal instructions with written operating procedures. Warm up this system with two operators in radio contact.

Determine exact opening requirement of the main steam valve through valve manufacturer data, then verify opening procedure by field test, write valve opening instruction on metal label, and attach this label on the valve hand-wheel.

Write a procedure to warm up the system in sections between valves instead of warming up total system in one operation.

Nondestructive Testing (NDT)

Conduct nondestructive tests on all welded joints between the 4" diameter strainer flange and 6" diameter pipe penetration - see Figure 8 (Appendix A). 


\section{$1.4 \quad$ DISCUSSION}

\subsubsection{Steam and Condensate System Description}

The ruptured strainer is a component in the steam supply system illustrated on Figures 1, 2, 3, and 9 of Appendix $A$. This system feeds steam to Building 309 through a 6 " diameter isolating valve in valve pit number 2 outsice Building 308. From this valve, steam flows through the 6" diameter underground pipe for 325 feet to the wall penetration in Building 309 . The pipe slope of the buried pipe in this section is opposite in direction to the steam flow. The wall penetration is below ground level. Inside the building the steam system is connected to a condensate drainage system consisting of: a condensate collecting leg, a steam trapping arrangement, and a steam trap bypass valve. Condensate from this drain system is pumped into the overhead condensate collection header by steam pressure. A 4" diameter building shutoff valve is the next item in the steam system followed by a 4" diameter elbow immediately upstream of the strainer.

Rupture of the strainer can be attributed to several separate factors all tied to the layout of the components in the unique system configuration described above. The discussion below describes each component separately and explains its role in the rupture incident. The sequence of the discussion follows the route of the steam flow starting with the isolation valve and ending with the steam strainer.

Several proposals are offered for the hardware modification of each component under discussion. However, the proposal that offers the best engineering resolution is always listed as "Proposal number l" followed by the next best engineering resolutions. 


\subsubsection{Oversized Isolation Valve}

The 6" diameter isolation valve is larger than required to serve the system. Under normal operating conditions the valve size is inconsequential, but, during system warm up the oversized valve is oversensitive at the lower opening range. This raises a concern for contrcl problems, such as greater steam flow than required and consequently greater condensate flows than the capacity to drain it. Figure 4 (Appendix A) illustrates the percentage of valve opening compared to system condensate formation and steam flow. It also shows the pipe line velocity.

The rate of condensate formation and the characteristics of a water reservoir downstream from the valve is shown in calculations - see Appendix $B$, Set $\frac{u}{\pi}$.

One of the characteristics of a gate valve is that the gate seats in a slot in the valve body. In the particular system configuration, this area is below the water level forcing the entering steam through a reservoir of water. This water comes from steam condensation during warm up and from water residue left in the pipe after cooling down of the system and is trapped next to the $6 "$ isolating valve by the slope of the pipe.

Proposed Hardware Modifications for Oversized Isolation Valve

Proposal " 1 - Install a 1/2" diameter warm up bypass valve around the 6" isolation valve.

\section{Advantages:}

Allows warm up with limited risk of water hammer damage.

Facilitates opening and closing of the isolation valve by equalizing the pres-sure across the valve gate - lessens seat damage - lessens leaks during shutdown. 
Steam erosion of valve seats are eliminated because the valve wil.1 no longer require partial opening (cracking).

One operator can warm up the system without the risk of initiating an uncontrollable situation.

Disadvantages:

Requires shutdown of the steam system to install the hardware.

Modification could be costly due to limited space in the valve pit.

Does not prevent the sudden ramping open of the isolation valve and the associated damage from severe water hammer.

Proposal $" 2$ - Leave the vaive as is and control the valve opening with approved operating procedures.

Advantages:

This is the most cost effective; the least disruptive.

This valve has been opened for warm up in a similar manner for years without any problems prior to the recent rupture incident.

Disadvantages:

There is always a high risk of sudden ramping open of the isolation valve and the consequences of resulting water hammer.

Requires two operators to keep control over the situation.

Steam erosion of high velocity wet steam through the small valve opening will ause erosion of the valve seats. 
Proposal $\# 3$ - Convert the present hand-whee: on the isolation valve to a gear operator mechanism with a 4 to 1 ratio spur gear.

Advantages:

Gives closer control over valve opening.

Reduces the risk of sudden ramping open of the isolation valve and lessen the associated risk of severe water hammer damage.

Allows opening and closing of the isolation valve using less effort from the operator.

Disadvantages:

Steam erosion of high velocity wet steam through the small valve opening will cause erosion of the valve seats.

Requires two operators to keep control over the situation.

Rapid closing of the valve during an emergency is not possible.

\subsubsection{Incorrect Direction of Slope of Steam Main}

The slope of the steam main, between the valve pit that houses the 6" valve and the pipe penetration to Building 309, is $0.5 \%$ over the total length of 325 feet. This slope is opposite in direction to the steam flow and therefore condensate tries to gravitate down to the low point in the pipe and steam attempts to form slugs of water to be released in the system.

The rate of condensate formation during warm up depends on the percentage of valve opening, and it also controls the steam velocity through the pipe. The combination of these features with the incorrect slope of the steam main sets up ideal water hammer conditions. 
Proposed Hardware Modifications for Correcting the Slope of the Steam Main

Proposal $\frac{\|}{\pi} 1$ - Leave the underground pipe as it is and control the flow of steam through the low lying portion by approved operating procedures.

Advantages:

This is the most cost effective; the least disruptive.

Disadvantages:

Does not eliminate the reservoir of water, the prime source of water slugs that could cause water hammer.

Proposal $\frac{\| 2}{\pi 2}$ - Install a condensate drainage systam near the 6" diameter isolating valve.

Advantages:

Eliminates water accumulation and lowers the probability of water hammer dama ge.

Disadvantages:

Modification will be costly. Condensate disposal is a problem.

Proposal \#3 - Excavate the steam main and aiter the slope.

Advantages:

El iminates the water reservoir and lowers the probability of water hammer dama ge. 
Disadvantages:

This is the least cost effective, in fact the cost is prohibitive. For a system that operated for years without recorded problems, this expenditure could probably never de justified.

\section{Water Hammer Narrative}

Unless condensate is removed from low points in a steam pipe, it will accumulate. Steam flowing over the low point at system operating velocity will cause ripples on the water surface - see Figure 7 (Appendix A); soon the ripples become waves, the steam passage will be restricted increasing the velocity; finally, a volume of water captured by the rushing steam will be carried forward in the pipe as a slug of water at steam flow velocity. The slug maintains this velocity, or increases velocity as consecutively smaller pipe diameters are encountered, until an obstruction is reached. At this Doint the water is brought to a sudden halt; kinetic energy is converted into pressure energy with a clear sounding ring and sometimes with associated damage.

Another form of generating wave formation is from "flashing flow". This occurs after the trapped condensate becomes saturated i.e., at its boiling point. During flashing flow several processes takes place: (1) the pressure decreases because of friction, (2) saturation temperatures decrease because pressure decreases, and (3) a portion of the condensate is vaporized because of the heat liberated by temperature reduction. Thus, two phase flow occurs with the ratio of the two continuously changing.

With sufficiently high steam velocities entering the system, a slug of water released by the flashing $c$ an be propelled down the steam main.

Another way of generating slug flow is by opening of the valve below the water level line, see Appendix $B$ - set 1 . Steam will then enter the system by displacing water in the steam main. This then dislodges a water slug or sets up wave formation that could develop into slugs. 
Irrespective of the initiating effects, it is clear that the steam main to Building 309 possessed the capabilities of gerierating water hammer from any of the above sources. Occupants in the building at the time of the incident confirmed that water hammer was characterized by random periodic impacts as upposed to cyclic two phase expansion anc contracting expected from flashing flow.

\subsubsection{Steam Main Pipe Diameter Variation}

Another sactor that affects the system perfomance during warm up is the change in pipe diameters. At the isolating valve the diamit.er is 6", the remainder of the unierground section is 6 " diameter. Inside the building, imediately after the wall penetration, the diameter changes to 4 ". With a constant pressure drop (and constant flow) through the isolating valve, the velocity of steam (or velocity of a water slug) will increase as it leaves the 6" pipe and enters the 4" pipe. However, the size of the water slug remains the same, therefore, the kinetic energy of the water slug increases in its path down the pipes, contributing another factor to a system that is aiready prone to severe water hammer damage.

\section{Proposed Hardware Modifications to Correct Steam Main Diameter Variations}

Proposal "य1 - Leave the system as it is and control the steam velocity below the danger levels with approved operating procedures.

Advantages:

The most cost effective; the least disruptive.

Disadvantages:

Does not eliminate the successive increase in velocities of steam and consequently the velocities of the water slugs. Severe water hammer damage is always just one turn of the valve hand-wheel from happening. 
Proposal $\frac{\|}{\pi 2}$ - Change the pipes in the system to pipe diameters that will keep the velocity below danger levels.

Advantages:

Eliminates high velocities in the steam main.

Disadvantages:

This is the least cost effective, in fact the cost is prohibitive. No engineering reason can be found that will justify the costs for changing the system.

\subsubsection{Undersized Condensate Collecting Leg}

Condensate collecting legs serves the purpose of accumulating water and settling the dirt in a system. These devices are constructed from the same size piping as the steam pipe, it is usually done by extending the pipe vertically downwards. Condensate collecting legs are instaiicd, in positions where pipes change directions vertically, or in low lying points of the system.

A collecting leg for Building 309 is located in the 6" diameter pipe after the wall penetration but upstream of the strainer as shown on figure 3 (Appendix A). The size of the collecting leg is approximately 4" diameter by 5 "long ( 0.036 cubic feet), during nomal system operation this volume is sufficient to handle the condensate drainage. However, during warm up condensation rates increases well above nomal. Nevertheless, the condensate collecting leg should be sized to receive the volume of a typical slug of water from the upstream system, in this case it is 0.24 cubic feet (15 lbs of water). Another feature of the collecting leg should be its ability to form a pocket that will not release trapped water to the onrushing steam, the collecting leg in question cannot perform this function. 
Proposed Hardware Modifications to Increase the Size of the Condensate Collection Leg

Proposal "1 - Change the present collecting leg to a 6" diameter $\times 30^{\prime \prime}$ long collecting leg.

Advantages:

This allows win. io with reduced risks of water hammer.

Facilitates a needed modification--installing a separate dirt leg with its own blow down.

Disadvantages:

Cost consideration.

Proposal $\# 2$ - Leave the system as it is and control the system warm up with approved operating procedures.

Advantages:

The most cost effective; the least disruptive.

Disadvantages:

Does no: reduce the risk of water slug carry over into the remainder of the system.

Does not eliminate the need for a dirt leg. 


\subsubsection{Steam Strainer}

\subsubsection{General}

Strainers are installed in steam systems to protect controlled orifices such as pressure reducing valves, control valves, and steam traps from dirt and debris primarily from construction activities immediately after a system start up. After this initial cleaning, the strainer collects dirt from pipe mill scale.

\subsubsection{Ruptured Strainer - Extent of Camage}

Water hammer in the form of water slugs ruptured the casing and separated part of the screen housin'y from the strainer proper, see figure 5 (Appendix A). Besides the damage to the rupture plane other cracks and some minor flaws were found in the casting. For a report on the extent of the total damage, see Appendix $C$.

The geometric configuration of the strainer forms a pocket in the system with a protrusion at the strainer entrance. This protrusion deflects high velocity water slugs into the screen housing. Water enters the strainer from the upstream elbow, which concentrates the flow on its outer wall in a direct path toward the strainer protrusion.

Water slugs entering the screen housing distributes the impact pressure evenly over the entire cavity due to the pocket of stagnant water trapped in the screen housing ( $y$ leg) of the stainer. This water remains in the strainer because no blowdown was installed on the strainer cap.

\subsubsection{Ruptured Strainer - Description}

The strainer is a 4" diameter, "Y" type, of Semi-Steel (gray cast iron) body construction, rated at 250 PSI, with flanged connections, Model AKC, manufactured by Armstrong Machine Works, 816 Maple Street, Three Rivers, MI. 
There was no screen in the strainer at the time of the rupture. This strainer was installed in the 4" steam line in Room $\# 8$ of Building 309 and forms part of the steam system that serves the comfort heating of the building. The strainer is approximately 17 " long and weights approximately 80 lbs. Strainer installation was during 1960.

\subsubsection{Ruptured Stainer - Replacement}

Substitute the temporary pipe spool, installed in the system after the rupture incident, with a 4" diameter, 250 PSIG rating, Y pipe strainer with a $\# 16$ mesh wire screen. Install the strainer replacement in the horizontal pipe 36" beyond the flange of the ell.

i.5 CRITIQUE OF OPERATING PROCEDURES AT THE TIME OF THIE STRAINER RUPTURE

\subsubsection{General}

The object in starting a system is to achieve warm up by increasing the temperature and pressure of a cold system within a reasonable time period; limit the formation of water slugs; reduce the mobility of these slugs; introduce steam into the system that will not overload the condensate drainage system.

\subsubsection{Limiting the Formation of Water Slugs}

Present operating procedures calls for opening the valve $3 / 4$ turn on the hand-wheel, this procedure is the same for all 6"diameter steam isolating valves in the 300 Area. This is unacceptable because this fixed amount disregards the fact that the valve is oversized for the system, the steam demand in this system can easily be satisfied by a 2" valve.

The same procedures also allow the opening of a steam valve by listening for a "Hissing" sound. This is also unacceptable because it is a purely 
judgmental action depending on each person's hearing ability and the extent of the background noises i.e., steam leaks in the valve pit could affect percentage of opening. Finally a hissing sound on an oversized valve could be a percentage opening beyond the condensate drainage requirements of the system.

\subsubsection{Developing an Approved Procedure for Opening the 6" Valve:}

If the system is io be warmed up without the proposed 1/2" diameter wamup bypass valve, then generate an operating procedure from the information listed below:

Study the characteristics of the valve from the manufacturers data, determine the number of turns to fully open the valve, determine the percent backlash, by calculation determine the safe opening percentage that will not overload the drain system, write a draft operating procedure, by field tests using sound amplification devices open valve to calculated amount, revise operating procedure, obtain approval for operating procedure, write caution tags and opening irstructions on a metal label and attach this label on the value handwheel.

\subsubsection{Reducing the Mobility of Water Slugs}

A conservative assumption is that there will always be water slug formation during warm up irrespective of the control measures taken. One way of reducing the mobility of the slugs is to confine their movement by isolating each section to be warmed up. The first section for the Building 309 system is between the two 6" diameter valves approximately 325 feet apart.

The recommended procedure to warm up this section:

"Crack" (slightly open) the 6" isolating valve to satisfy the warm up
requirements of the isolated section, drain the system of condensate
and then crack the 6" building valve while leaving the 6" isolating
valve cracked. Warm up the next section of system in a similar fashion. 
This procedure greatly reduces the risk of damage from slug formation and will result in a controllable condition for the operators.

\subsubsection{Limiting Flow Within Orainage Capacity}

The draining of a supervised warmup steam system is usually designed for normal system operation where condensate formation is well within the limits

of the steam trap. However, during warm up the steam trap cannot cope with the high demand and therefore the bypass valve is manually opened, this reduces the pressure in the steam main to near atmospheric. Nevertheless, the system is designed for lifting condensate from the collection leg to the overhead drain header, this requires a pressure differential. The present operating procedure aggravates the situation by opening additional bypasses downstream that deteriorates the pressure differential condition. Finally the drain system becomes overloaded due to insufficient differential pressure, allowing the formation of water slugs and increasing the risk of water hammer.

Opening of the $6 "$ isolating steam valve to an approved procedure can limit condensate formation and if warming up of the system is carried out in sections then the system will be at a higher pressure level and the concern for over-loading the condensate drain system will be eliminated. 


\section{SECTION 2}

The steam distribution system of the 300 Area may have components that could be vulnerable to water hammer during the system warm up mode, similar to the water hammer rupturing of the 4" strainer in Building 309. To this date no survey has been conducted to locate such potential problems.

Finding these vulnerable components that could be subjected to severe water hammer, resulting in possible breaching of the pressure boundary, analyzing the system for possible solutions, and proposing recommended steam system modifications is the object of this review.

A survey, utilizing the findings of the engineering evaluation in section 1 of this report, was conducted on all the high pressure steam connections to the buildings, see figure 9 (Appendix A). This survey investigated potential ruptures in large steam components ( 3 "diameter and larger) on the high pressure side of the components (125 PSIG), with special emphasis placed on potential personnel injuries.

This is a paper study attempting to establish the extent of the problem. Details of individual component defects may surface during non-destructive testing activities.

Requirements of item " 9 of Unusual Occurrence Report 82-25, "Line Rupture During Introduction of Steam Into a cold Header," is satisfied by Section 2 of this report.

\subsection{ITEMS NOT INCLUDED IN THE SURVEY}

The survey was limited to visual inspection of components in operating systerns. 
Component manufacture and model numbers could not be identified due to the thermal insulation covering these items.

Items on systems 2-1/2" diameter and smaller were not investigated because the volume of water slugs in pipes of this size present no rupture threat.

Components downstream of pressure reducing stations were not surveyed because water slug movement beyond these items are unlikely.

Building 384 (Power house) components were not surveyed.

\section{$2.2 \quad$ CONCLUSION}

The survey could not find any other configuration of system components in the 300 Area steam distribution system with a similarly high potential for boundary pressure rupture as in the Building 309. However, several systems were found with potential water hammer problems. See Table 1 at the end of Section 2 for the listing of 300 Area buildings with 3 -inch and larger diameter steam supply lines and the various risk categories.

\section{$2.3 \quad$ RECOMMENDATIONS}

Install small size bypass warmup valves on all valves 3" diameter and larger and with a high risk of water hammer during warmup. The valves with a lower potential for water hammer problems can be kept under control by approved operating procedures similar to the recommendations as given in section 1 , "Critique of Operation Procedures."

Conduct Nondestructive Testing on systems with components having large, flat surface areas and which are exposed to high risks of water hammer during warmup, i.e., large bore strainers. 
All buildings occupied by Westinghouse and supplied with steam were surveyed; this excludes all sizes of steam pipes 2-1/2" diameter and less. These systems were surveyed from the point where the pipe enters the building to the heating apparatus or to the nearest pressure reducing station.

Systems downstream of the pressure reducing stations were not. looked at because water slugs passing through these stations cannot be of large volume and, therefore, cannot present a water hammer problem.

Systems with pipe sizes 2-1/2" diameter and smaller were ignored because the volume of water slugs in these systems do not have the Kinetic energy to cause a severe water hammer problem. Furthermore, the rigidity of the components in these systems make them stronger than the equivalent components found in large bore systems.

The survey was conducted with an Operations Supervisor as a guide. Visual inspection of individual components were severely limited due to the thermal insulation; for instance, it was not possible to identify the manufacturer, the model number, or the size. However, the relative locations of the components were clearly visible.

Table 1 at the end of Section 2 lists all buildings with steam pipe connections 3" diameter and larger and evaluates the pertinent factors that could contribute to water hamer damage.

Potential water hammer problems are possible by any of the following combinations:

- No building shutoff valve + large or complex system in building

- No building shutoff valve + inadequate drainage

- Pipe slope against steam flow + inadequate or no drainage

- Pipe slope against steam flow + long pipe (>100 ft) 
Seven out of fifteen buildings have a high putential for water hammer problems:

- Building 306 - Does not have one central building shutoff valve and consists of several large systems on high pressure steam (125 psig).

However, the building is on permanent steam requiring closing down and warming up only during repairs and maintenance.

- $\quad$ Building 308 - Same characteristics as Buiiding 306.

- Building 309 - There are two steam supply lines connected to this building; the one connection was thoroughly covered in Section 1 of this report. The other connection is a 4" diameter steam system with an adequate sized drain and a very short high pressure steam pipe inside the building before entering the pressure reducing station.

- Building 321 - There are three steam supply lines connected to this building; only the 4 " connection on the west side serving 3218 has a water hammer potential. This building does not have a central building shutoff valve and several large tanks are continuously supplied with steam. Water hamer could only be a problem during subse- quent warmup after repair and maintenance shutdowns.

- Building 324 - The steam supply line connected to this building is very short, and without adequate drainage, water hammer could become a problem. This building is continuously supplied with steam and water hammer is expected only during warmup after repairs and maintenance.

- Building 326 - The steam supply line connected to this building is very long (approximately 300 feet), and the pipe slope is against the steam flow, but the condensate drainage in the building is adequate. Therefore, the system does have a potential water hammer risk. This building is continuously supplied with steam, and water hammer is expected only during the warmup after repairs and maintenance.

- Building 327 - The steam supply line connected to this building is short (less than 100 feet); there is good drainage, but the slope of the steam main is opposite to the steam flow. Therefore, water hammer is a probability during warmup. 
Install small size by-pass warm up valves on 3" diameter and larger isolating valves in systems with a high risk of water hammer as indicated on Table 1. The remainder of the steam systems can be controlled by proper operating procedures similar to the recommendations given in section I, "Critique of Operating Procedures."

Personnel injuries are noi. likely because no high fressure steam main passes through occupied office space. 


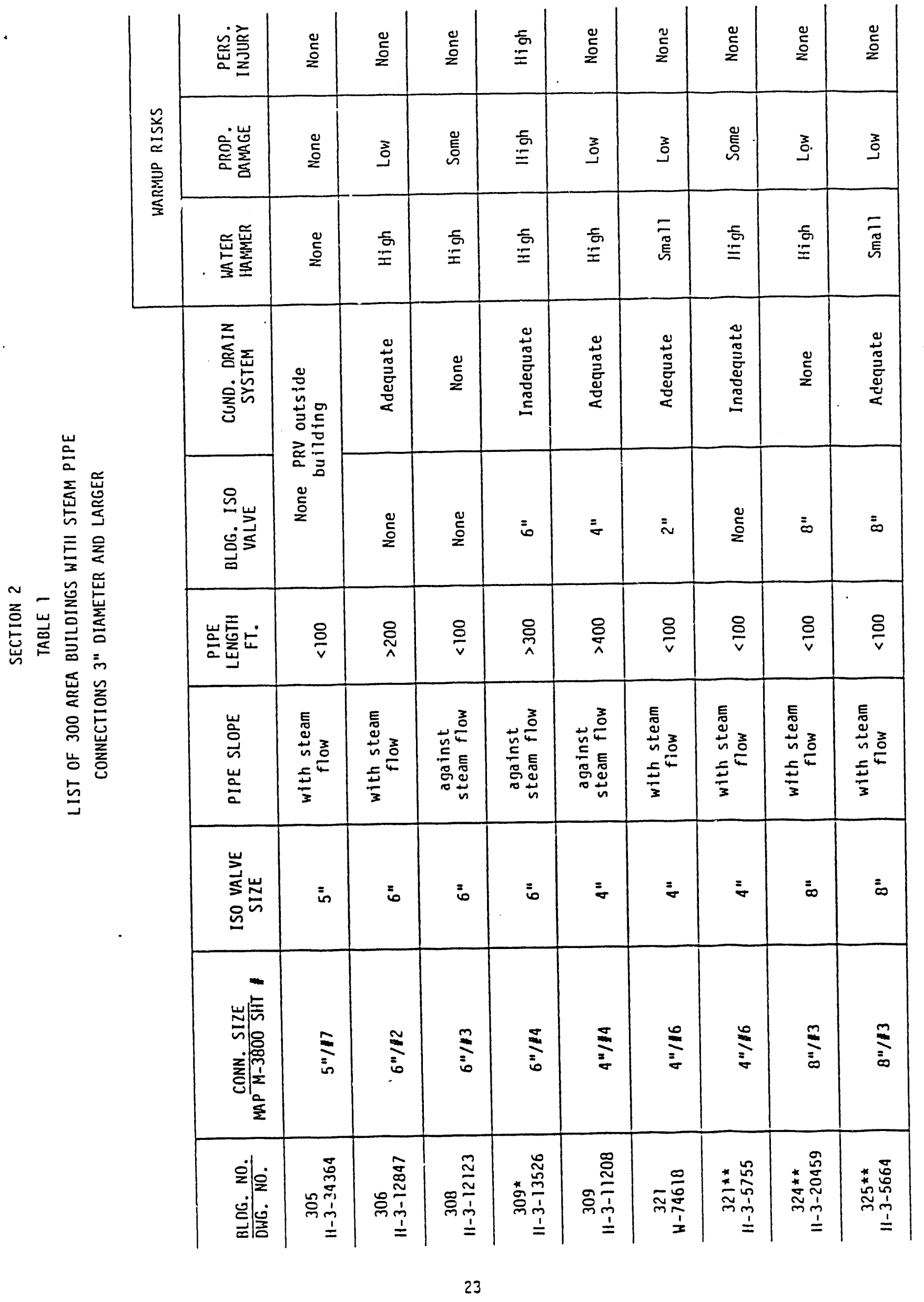




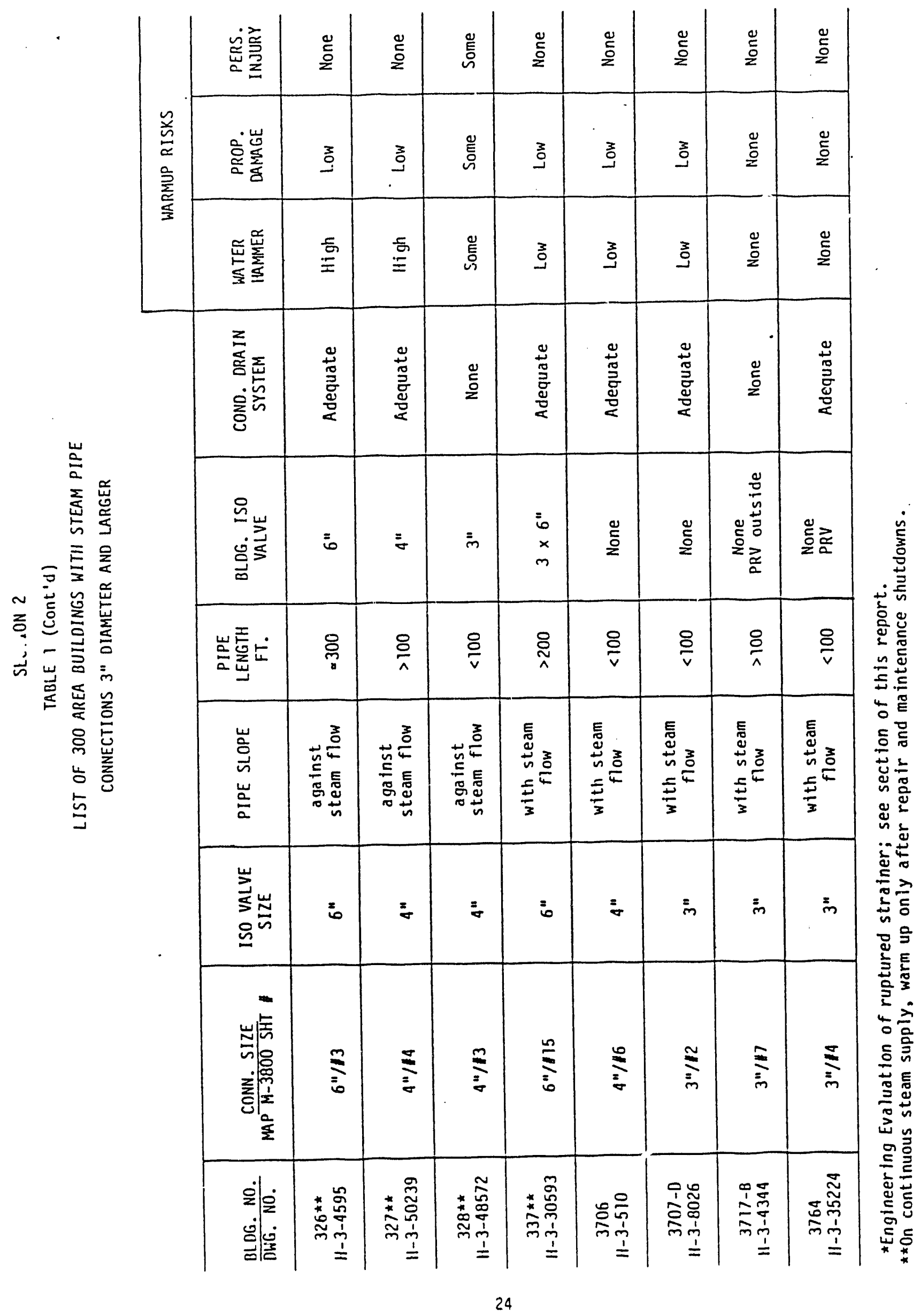




\section{APPENDICES}

APPENOIX A Contains all the Drawings and Sketches Referred to in the Body of the Report.

Fig. 1 - Plot Plan of Builúing 309 Steam Supply System

Fig. 2 - Diagrammatic Piping Configuration of Steam Components From Valve Pit $\frac{\|}{\pi} 2$ to Building 309

Fig. 3 - Piping Configuration of Steam \& Condensate Component: in Room $\frac{\|}{\pi} 8$, Building $309^{\circ}$

Fig. 4 - Valve Curve - Hand-wheel Turn vS $\%$ Valve Opening

Fig. 5 - Illustration of Strainer Damage

Fig. 6 - Strainer Description

Fig. 7 - Water Hammer Sequence

Fig. 8 - Path of High Velocity Water Slugs

Fig. 9 - 300 Area Main Service Steam

APPENDIXB - Contains All the Calculations and Tables Used in This Report.

Calcuiation Set 1 - Determining Water Amounts in Building 309 Steam Main

Calcliation Set 2 - 8" Diameter Valve Opening Characteristics Steam Flow and Steam Velocity Caic's

Table I

- Warmup Load Per 100 Feet of Steam Main

Table II

- Condensation Load to Maintain Pressures and Temperature

APPENDIX C - Contains the List of Reports Referenced in the Engineering Evaluation.

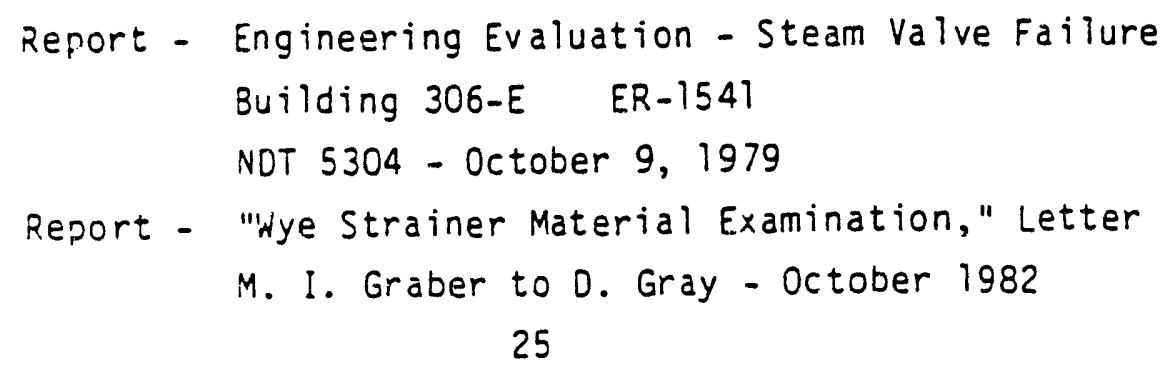




\section{APPENDIX - B}

\section{Calculations Set $\#$ I}

The calculations below determine the amounts of water in the steam main between valve pit $\# 2$ and Building 309 and establishes the depth of water in the steam main to evaluate the performance of the 6 " steam valve during the rupture incident.

Diameter of pipe is 6" immediately downstream of the valve and 6" diameter for approximately $325 \mathrm{ft}$ (between valve pit and Room $\# 8$ ).

$$
\begin{aligned}
\text { Volume of pipe } & =325 \times .196 \mathrm{ft}^{3} \text { per ft } \\
& =63.8 \text { cubic ft }
\end{aligned}
$$

Amount of trapped water when the system cooled down with 125 psig saturated steam inside the pipe.

From steam tables specific volume at
125 PSIG
$=3.220$ cubic $\mathrm{ft} / \mathrm{lb}$ for saturated vapor
Total weight of water
$=\frac{63.8}{3.22}=19.81$ lbs of condensate

Temperature of water before warm up is approximately $60^{\circ} \mathrm{F}$.

Assume a system pressure of 5 PSIG during warm up, i.e., $228^{\circ} \mathrm{F}$ and 960 BTU'silb for latent heat of steam.

Steam required to heat 19.81 lbs of water

$$
=\frac{19.81(228-60)}{960}=3.46 \text { lbs of steam }
$$


Steam load to warm up the mass of piping with 5 PSIG steam:

From Table I (Appendix A)

$$
\text { Steam in lbs } \quad=\frac{325}{100} \times \underline{35.9}
$$

Warm up of Steel Pipe $=117$ lbs of steam or lbs of condensate

Total amount of condensate in pipe at end 'of warm up period.

$$
\begin{aligned}
\text { Total condensate }= & \text { Cool down water load + steam to warm up } \\
& \text { water }+ \text { warm up steel pipe } \\
= & 19.81+3.46+117 \\
= & 130 \text { lbs of condensate collected }
\end{aligned}
$$

To find the total area of the gate (in the gate valve) under the water line

The slope of the pipe is $0.5 \%$

Therefore height difference

$$
\begin{aligned}
\text { over total length } & =0.005 \times 325 \times 12 \\
& =19.5^{\prime \prime} \text { total }
\end{aligned}
$$

To cover a 6" pipe will require a length of pipe $L$ feet if water fills half the pipe length $(L)=\frac{6^{\prime \prime}}{.005} \times 12=100$ feet

The weight of water in a 6" pipe 1 foot long filled with water

$=12.51 \mathrm{lbs}$ 
$1 / 2$ the weight of water in a 6" diameter pipe $100 \mathrm{ft}$ long

$$
=100 \times \frac{12.51}{2}=625.5 \mathrm{lbs}
$$

Twenty percent of this total volume is approximately equal to the amount of condensate collected during warm up.

This shows that a large percentage of the opened portion of the gate (from the gate valve) will be under the water level line, therefore, steam will have to displace water to enter the system. 
The calculation below determines the velocity of steam or water in the 4" diameter pipe during the rupture incident.

Characteristics of 6" diameter gate valve total number of turns to open the valve $=35$ turns

$$
\text { Total lift per turn }=\frac{6}{35} \quad=0.171 \text { inches }=r-x
$$

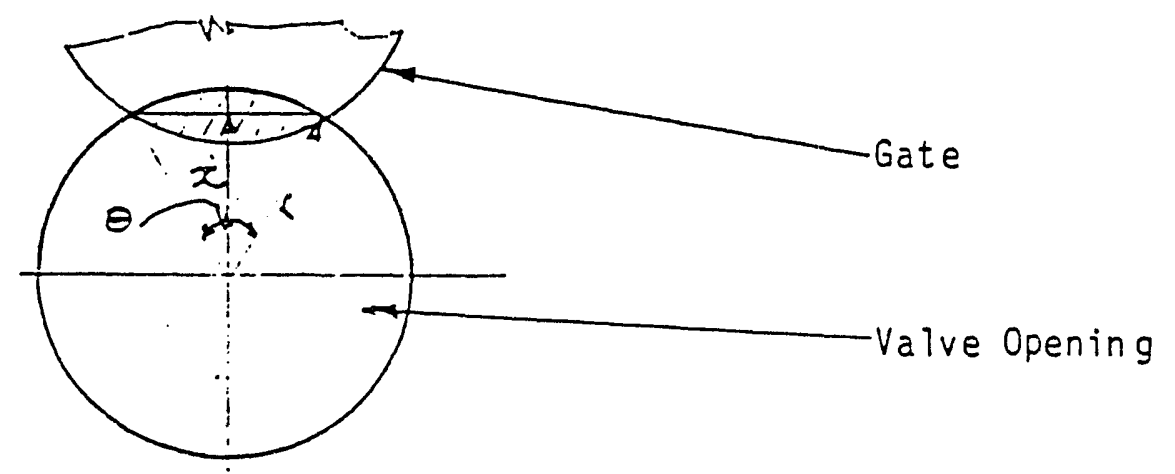

Area of Sector -

Area of gate $=2 \times$ area of sector

Area of Pipe Opening

Valve Opening for 1 turn $=\frac{r^{2}}{2}(\theta-\sin \theta)$

$=2 \frac{r^{2}}{2}(\theta=\sin \theta)$

= Pipe area - gate area

$=\pi r^{2}-r^{2}(\theta-\sin \theta)$

$=\pi 3^{2}-3^{2}\left(\frac{176}{56.3}-\sin 176\right)$

56.3

$=1.256$ Square Inches 
As sume velocity of 24,000 FPM across open valve area

$$
\begin{array}{ll}
\text { Volume of flow thru valve } & =\frac{24,000}{3.22} \times \frac{(1.256)}{(144)} \times 60 \\
\text { opened one full turn } & \\
\text { One full valve turn } & =3786 \mathrm{lbs} / \mathrm{hr}
\end{array}
$$

Assume 3/4 turn (Operators Al lowable Total Opening per Operating Instructions)

$=2838 \mathrm{lbs} / \mathrm{hr}$

Velocity in 6" pipe before expanding $=\frac{1.256}{28.23} \times 24000=1036 \mathrm{FPM}$

The expansion ratio of steam from 125 PSIG to 5 PSIG is:

$=\frac{20.09}{3.22} \quad=6.24$

$\begin{array}{ll}\text { The average velocity in 6" pipe } & =6.24 \times 1036=6468 \mathrm{FPil} \\ \text { Therefore for a 4" pipe velocity } & =\frac{6^{2}}{4^{2}} \times 6468 \quad=14,553 \mathrm{FPM}\end{array}$

Assume water slug weighs 15 lbs then Kinetic Energy will be:

$$
\begin{aligned}
K E & =\frac{1}{2} \frac{15}{32.2}\left(\frac{14,553}{60}\right)^{2} \\
& =13,700 \text { FT-LBS }
\end{aligned}
$$




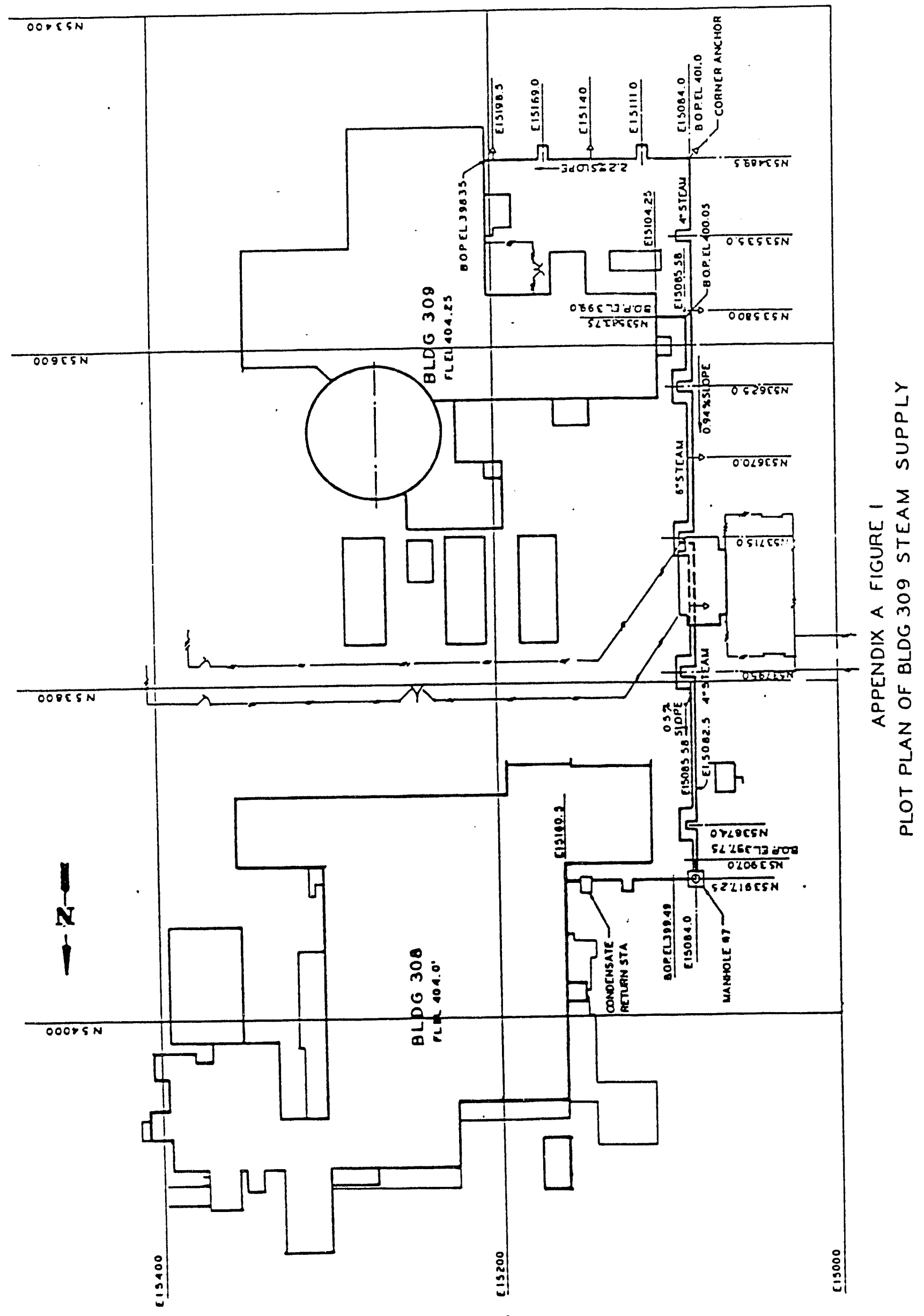




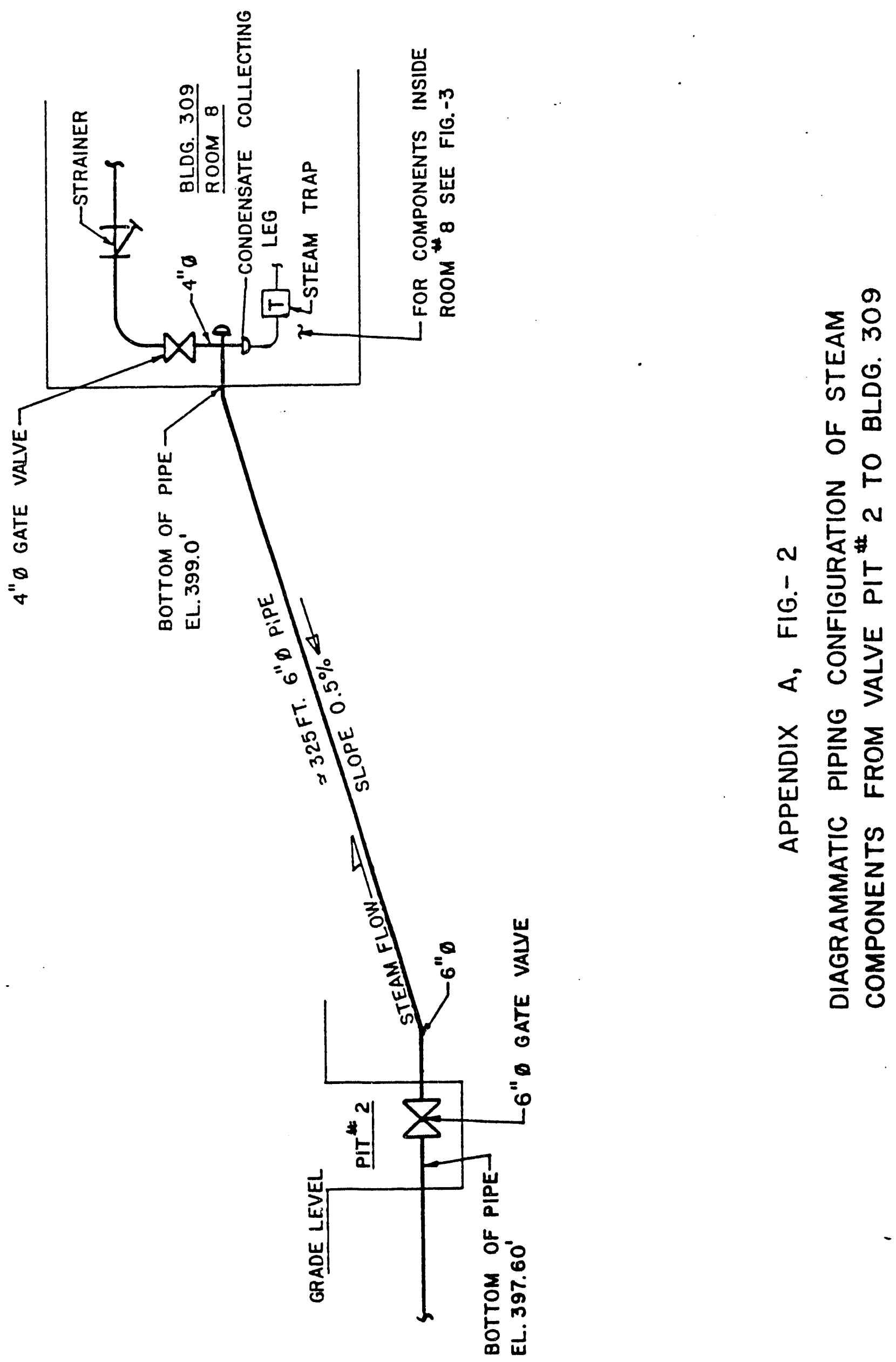




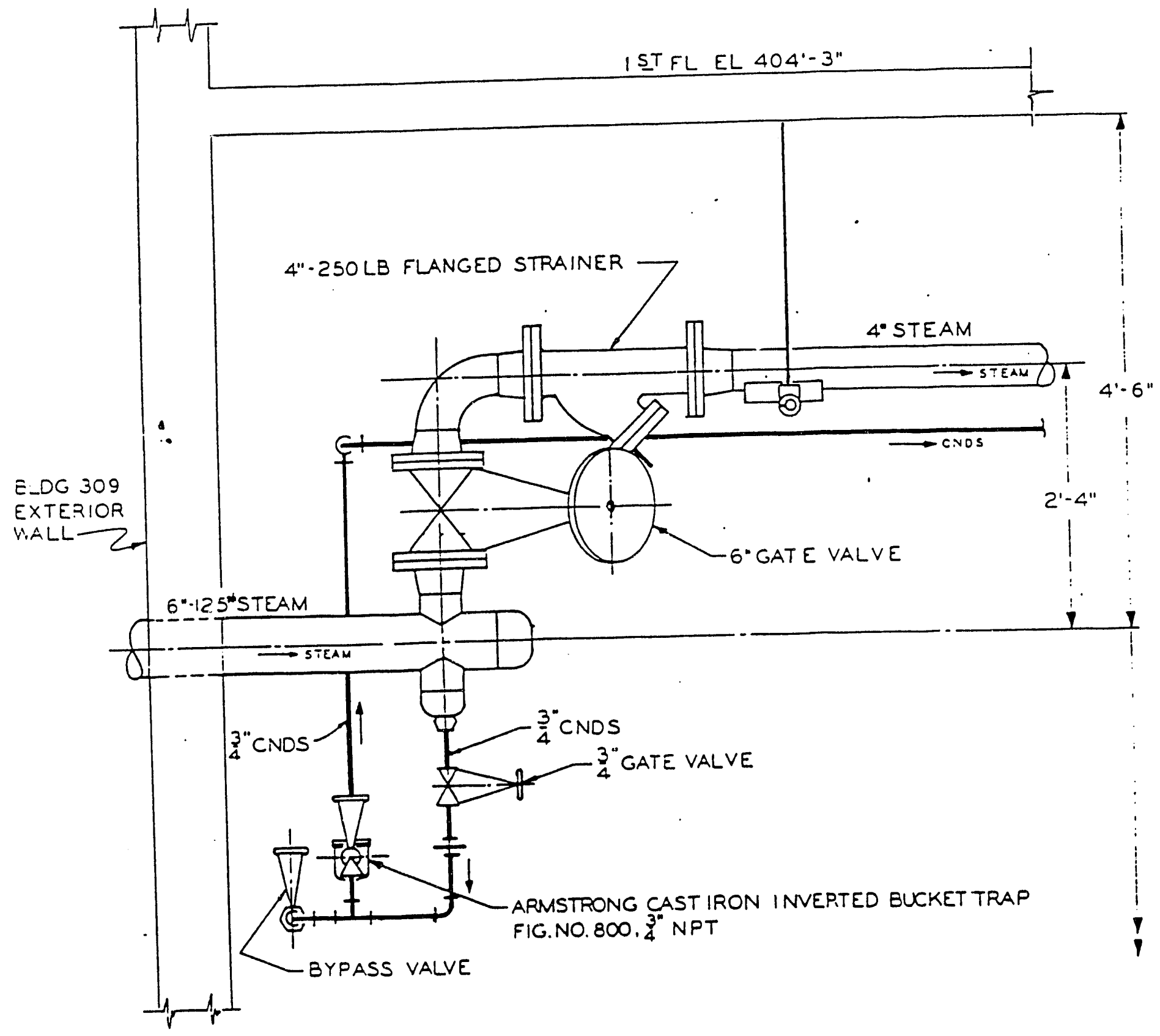

PIPING CONFIGURATION OF STEAM \& CONDENSATE COMPONENTS IN ROOM $\# 8$ BUILDING 309 
APPENDIX A - FIG 4

VALVE CURVE-HANDWHEEL TURNS VS PERCENT

VALVE OPENING WITH SYSTEM VENTED TO ATMOS PHERE

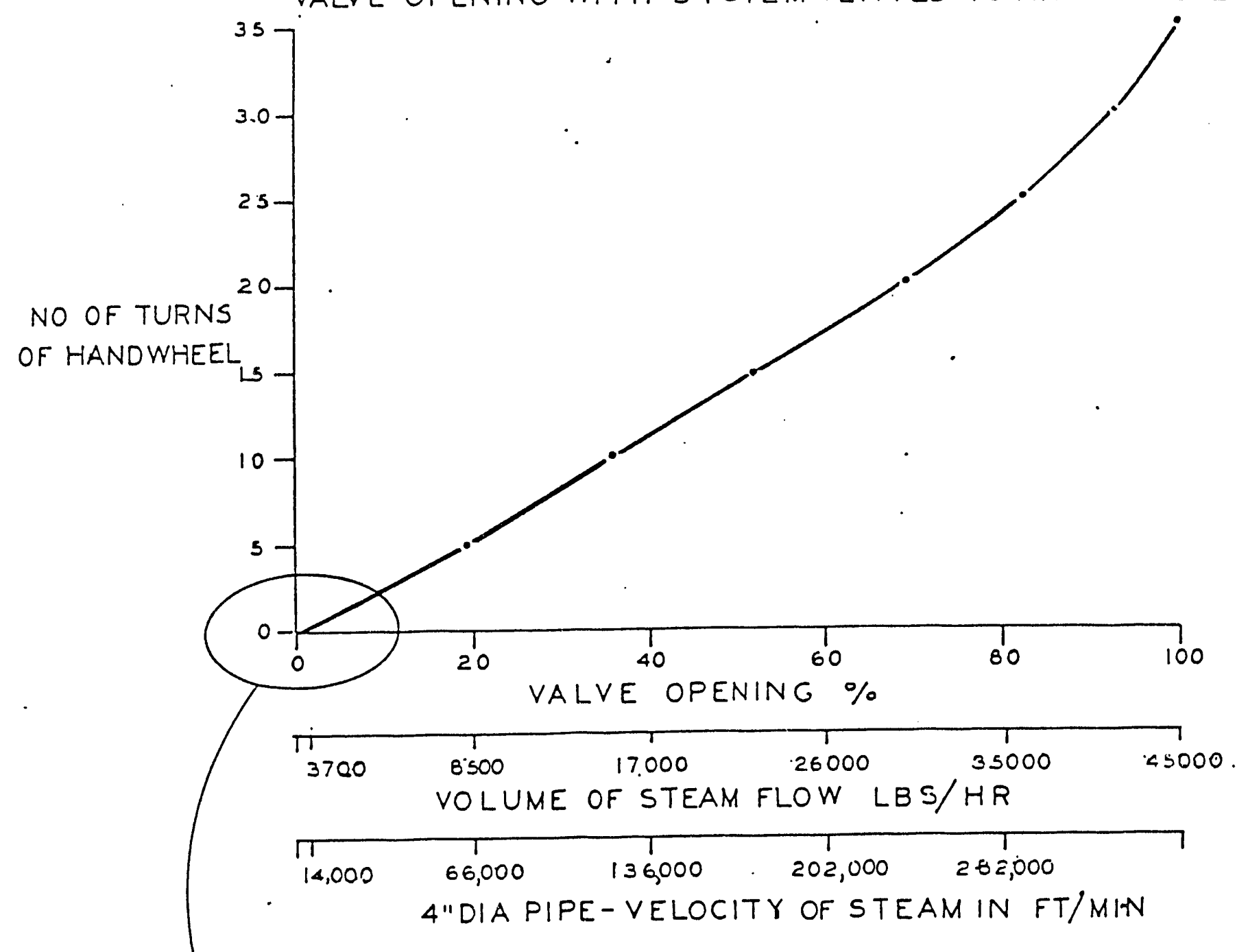

NO OF TURNS, OF HANDWHEEL

VELOCITY OF STEAM IN FV/MIN - 4"DIA PIPE MENTS $=100 \mathrm{LBS} / \mathrm{HR}$ @IPSI

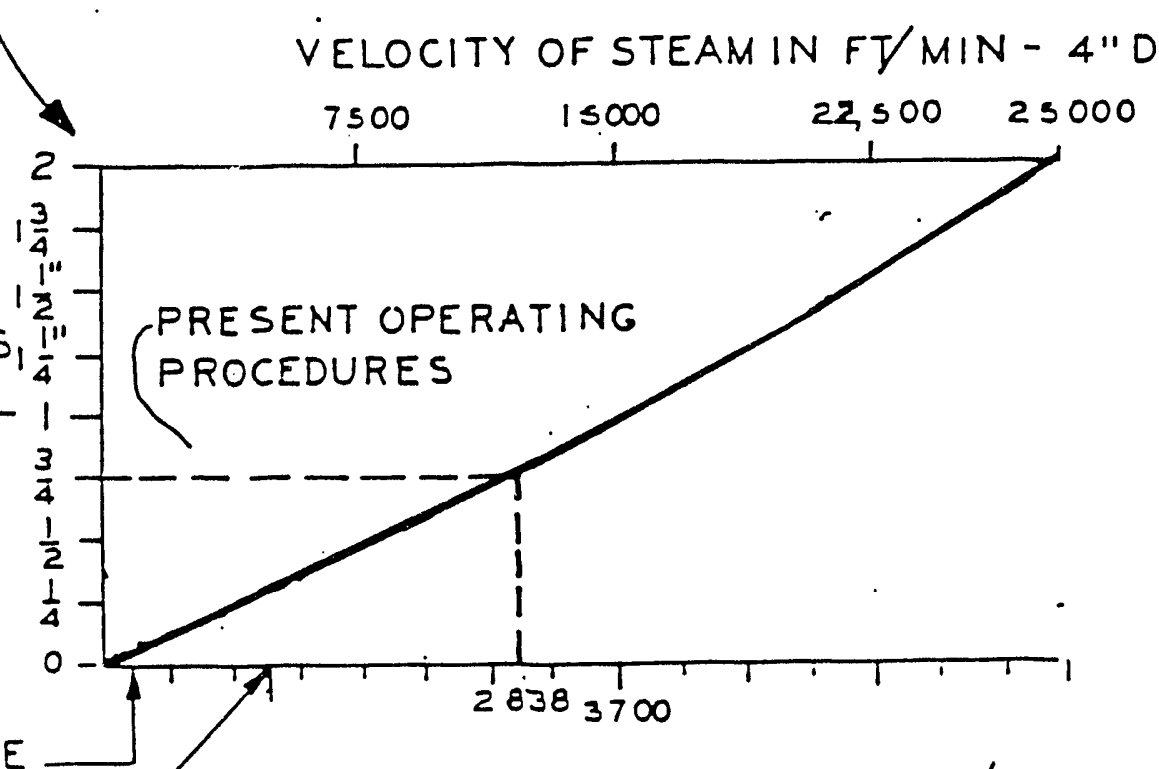

VOLUME OF STEAM FLOW IN LBS/HR $\frac{3}{4}$ "CONDENSATE DRAIN CAPACITY 1265 LBS/HR e। PSI 
DRAWING DEPICTS COMPILATION OF METALL OGRAPHIC INFORMATION FOUND ON HEDL X-RAY REPORT \#8168.

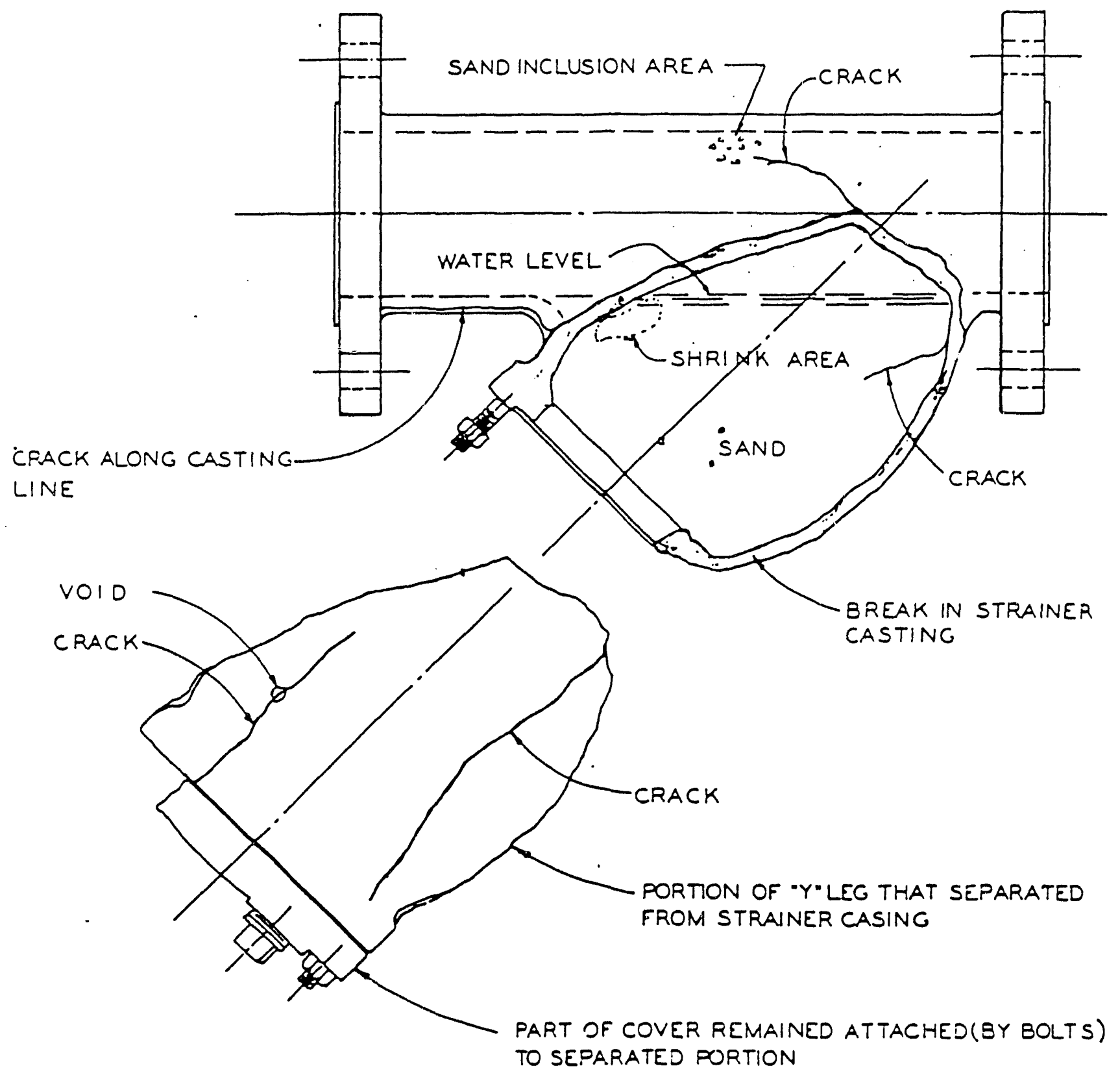

APPENOIX A FIGURE 5

ILLUSTRATION OF STRAINER DAMAGE 


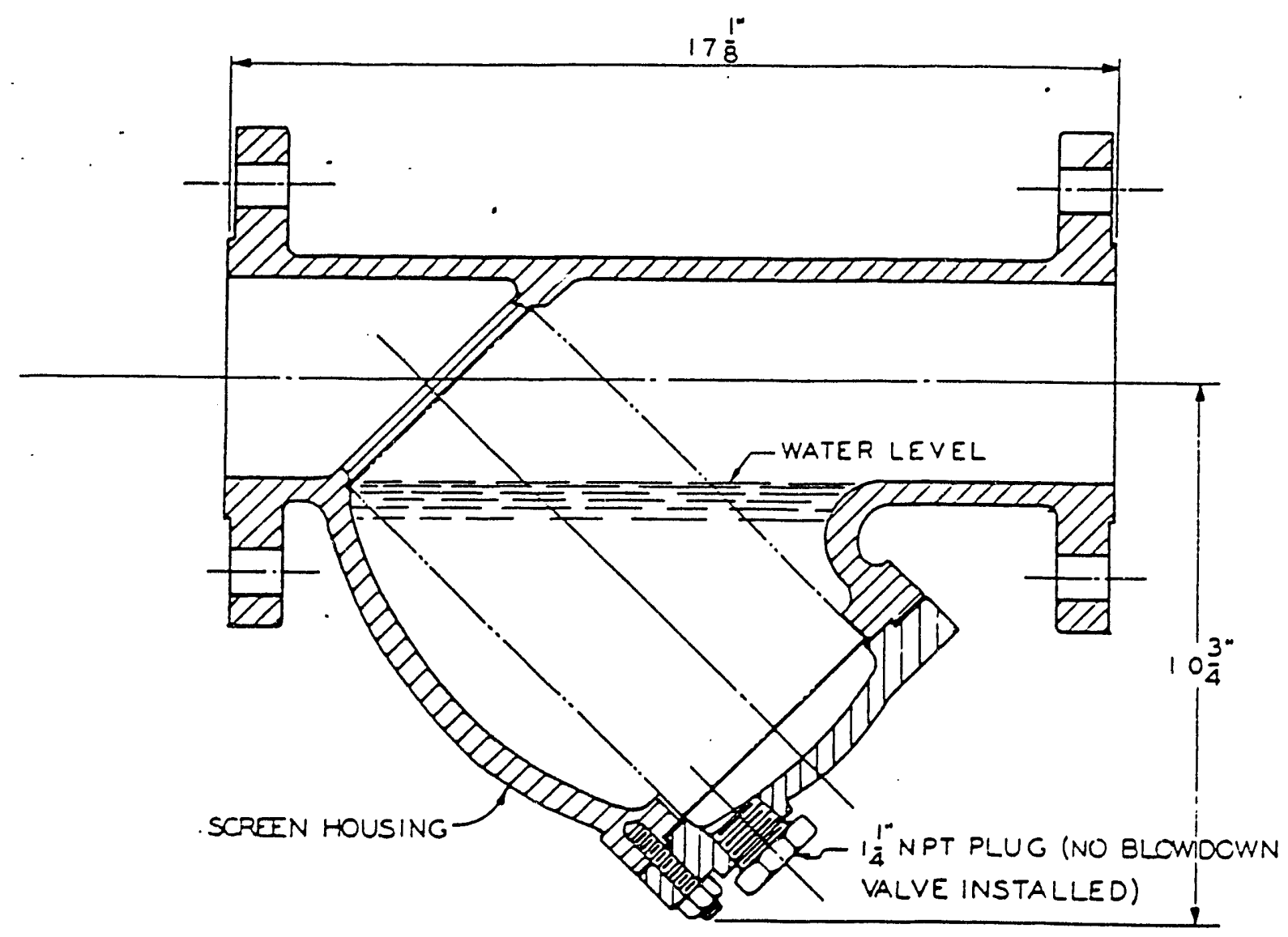

4"-250" SEMI-STEEL"Y" TYPE STRAINER ARMSTRONG MACHINE WORKS FG AK-4

APPENDIX A FIGURE 6 

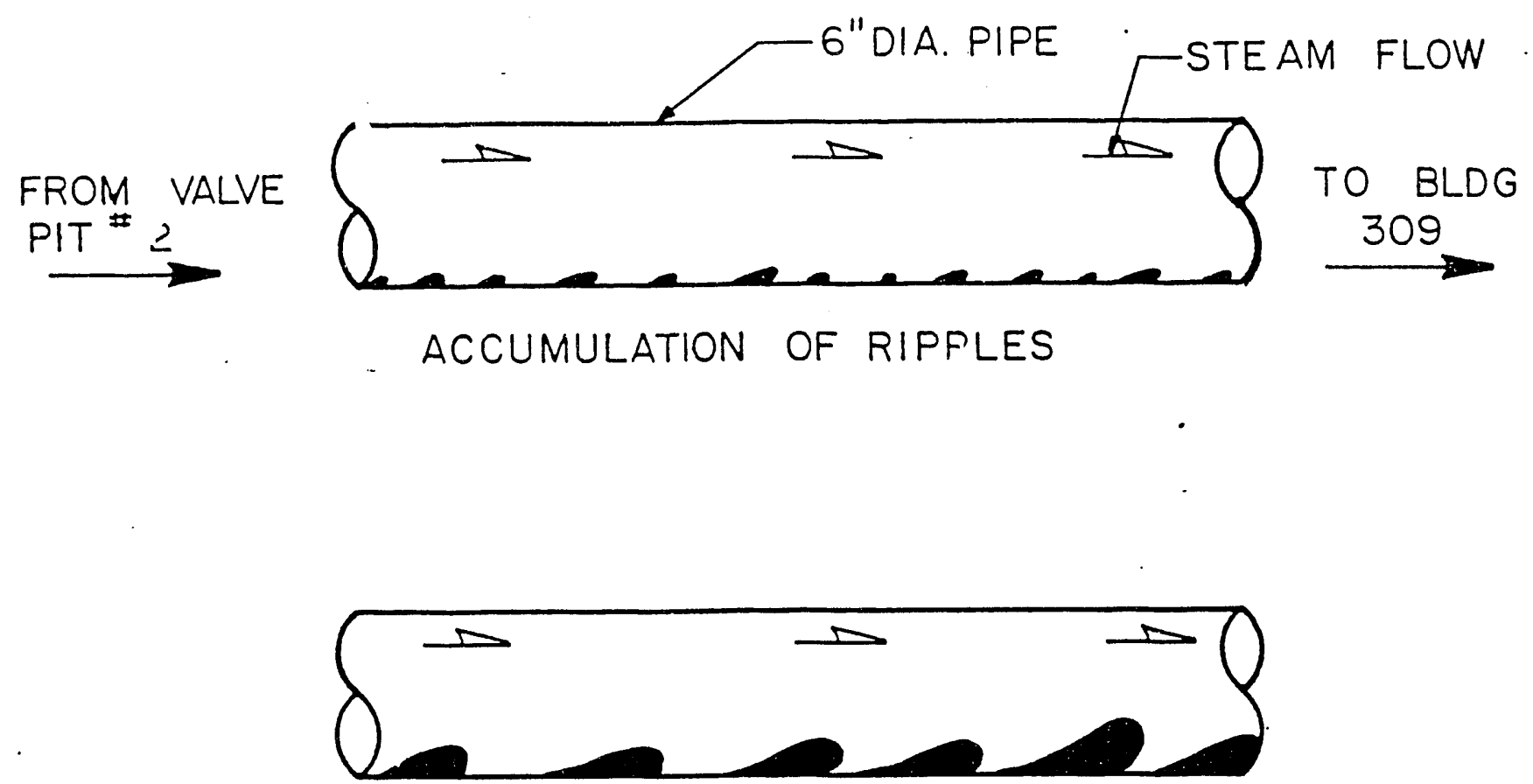

FORMATION OF WAVES

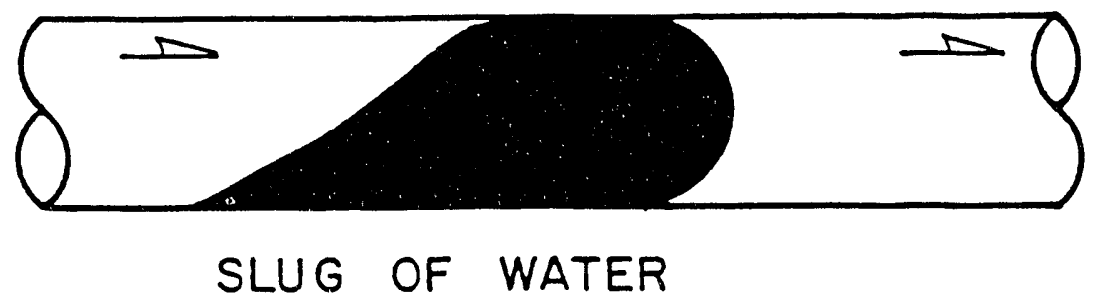

PROGRESSIVE BUILD-UP OF CONDENSATE THAT PRODUCES WATER HAMMER.

APPENDIX A, FIG.-7

WATER HAMMER SEQUENCE 


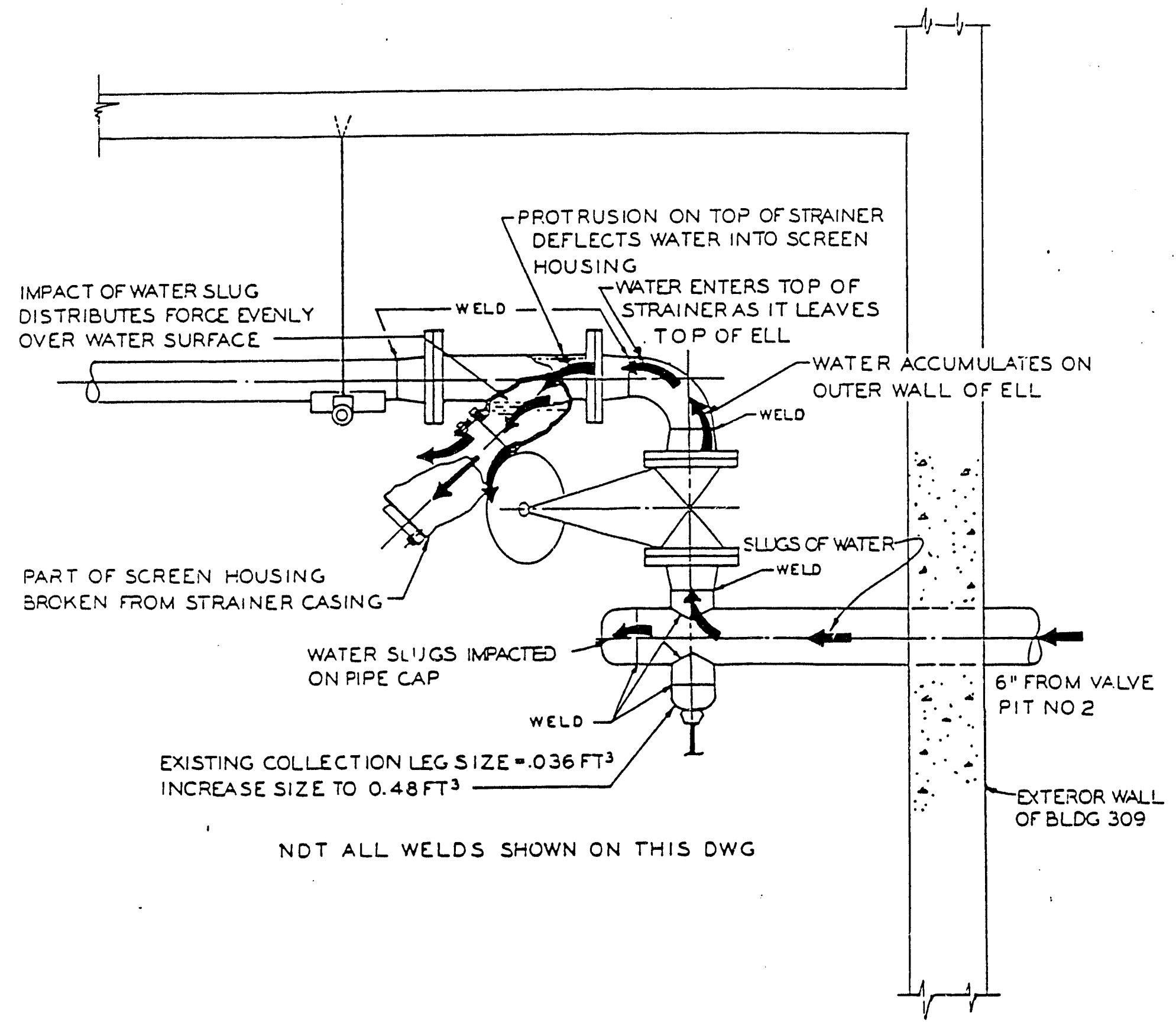

PATH OF H IGH VELOCITY WATER SLUGS 


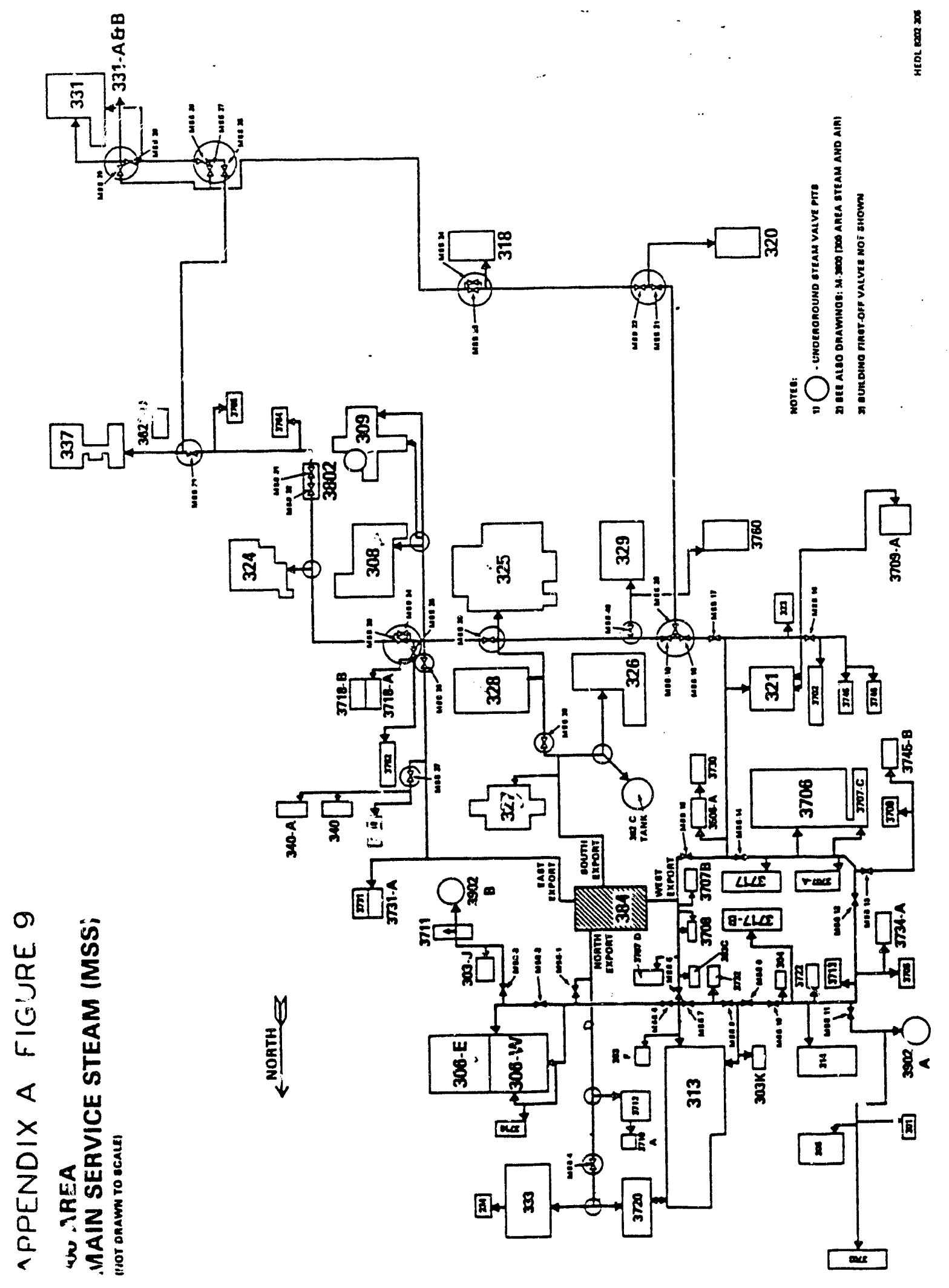


Steam

Piessure

(PSIG)

0
5
10
20
40
60
80
100
125
150
175
200
250
300
400
500
600

$2021 / 20^{\infty} \quad 3^{\infty} \quad 4^{\infty} \quad 5^{\infty}$

WARM-UP LOAD IN POUNDS OF STEAM PER 100 FEET OF STEAM MAIN - AMBIENT TEMPERATURE $70^{\circ} \mathrm{F}^{\circ}$

MAIN SIZE

$0 \circ \mathrm{F}$.

Correction

$\begin{array}{llllllllllllll}6.2 & 9.7 & 12.8 & 18.2 & 24.6 & 31.9 & 48 & 68 & 90 & 107 & 140 & 176 & 207 & 208\end{array}$

1.50

$\begin{array}{lllllll}6.9 & 11.0 & 14.4 & 20.4 & 27.7 & 35.9\end{array}$

$48 \quad 77$

$101 \quad 120 \quad 157$

$198 \quad 233 \quad-324$

1.44

$\begin{array}{lllllll}7.5 & 11.8 & 15.5 & 22.0 & 29.9 & 38.8\end{array}$

$\begin{array}{llllll}58 & 83 & 109 & 130 & 163\end{array}$

$213 \quad 251 \quad 350$

.1 .41

$\begin{array}{llllll}8.4 & 13.4 & 17.5 & 24.9 & 33.8 & 43.9\end{array}$

$\begin{array}{lllll}66 & 93 & 124 & 146 & 191\end{array}$

$241284 \quad 396$

1.37

$\begin{array}{lllllll}9.9 & 15.8 & 20.6 & 29.3 & 39.7 & 51.6\end{array}$

$\begin{array}{lllllll}11.0 & 17.5 & 22.9 & 32.6 & 44.2 & 57.3\end{array}$

$78 \quad 110$

145

$284 \quad 334 \quad 465$

1.32

$\begin{array}{llll}12.0 & 19.0 & 24.9 & 35.3\end{array}$

47.962 .1

$86 \quad 122$

162

$172 \quad 225$

$316 \quad 372 \quad 518$

1.29

$\begin{array}{lllll}12.8 & 20.3 & 26.6 & 37.8\end{array}$

$\begin{array}{lllll}13.7 & 21.7 & 28.4 & 40.4\end{array}$

51.266 .5

$93 \quad 132$

188

208271

$342403 \quad 561$

1.27

$\begin{array}{lllll}14.5 & 23.0 & 30.0 & 42.8\end{array}$

$54.8,71.1$

$\begin{array}{ll}100 & 142 \\ 107 & 152\end{array}$

200

$222 \quad 290$

366

$\begin{array}{cccc}58.0 & 75.2 & 113 & 160 \\ 61.2 & 79.4 & 119 & 169\end{array}$

212

$\begin{array}{lllll}15.3 & 24.2 & 31.7 & 45.1\end{array}$

$16.0 \quad 25.3$

$17.2 \quad 27.3$

$25.0 \quad 38.3$

$27.8 \quad 42.6$

$30.2 \quad 46.3$

33.147 .1

$\begin{array}{llll}61.2 & 79.4 & 119 & 169 \\ 63.8 & 82.8 & 125 & 177\end{array}$

224

$251-328$

391

431

600

1.26

1.25

1.24

1.23

1.22

1.21

$\begin{array}{lllllll}35.8 & 50.8 & 68.9 & 89.4 & 134 & 191 & 252\end{array}$

$277 \quad 362$

$437 \quad 514 \quad 716$

$456 \quad 537 \quad 748$

$492 \quad 579 \quad 807$

1.20

$\begin{array}{lllllll}57 . j & 83.2 & 115.7 & 158.7 & 241 & 358 & 493\end{array}$

531682

$854 \quad 1045 \quad 1182$

1.18

32.750 .1

$\begin{array}{lllll}62.1 & 90.5 & 125.7 & 172.6\end{array}$

262

$590 \quad 759$

$971 \quad 1163 \quad 1650$

1.17

600

- Loads based on Schedule 40 pipe for pressures up to and including 250 PSIG and on Schedule 80 pipe for pressures above 250 PSIG.

†For outdoor temperature of $0^{\circ} \mathrm{F}$. multiply load value in table for eaçh main size by correction factor corresponding to steam pressure.

\section{TABLE II}

CONDENSATION LOAD IN POUNDS PER HOUR

PER 100 FEET OF INSULATED STEAM MAIN*AMBIENT TEMPERATURE $70^{\circ}$ - INSULATION $80 \%$ EFFICIENT

Steam.

MAIN SIZE

O०F.

Pressure

\begin{tabular}{|c|c|c|c|c|c|c|c|c|c|c|c|c|c|c|c|}
\hline $\begin{array}{l}\text { Pressure } \\
\text { (PSIG) }\end{array}$ & $2^{\infty}$ & $21 / 2^{-}$ & $3^{-}$ & $4^{-}$ & $5^{\infty}$ & 6" & $8^{-}$ & $10^{-}$ & $12^{\infty}$ & $14^{\circ}$ & $16^{\circ}$ & $18^{\circ}$ & $20^{\circ}$ & $24^{\infty}$ & Factort \\
\hline 10 & 6 & 7 & 9 & 11 & 13 & 16 & 20 & 24 & 29 & 32 & 36 & 39 & 44 & 53 & 1.58 \\
\hline 30 & 8 & 9 & 11 & 14 & 17 & 20 & 26 & 32 & 38 & 42 & 48 & 51 & 57 & 68 & 1.50 \\
\hline 60 & 10 & 12 & 14 & 18 & 24 & 27 & 33 & 41 & 49 & 54 & 62 & 67 & 74 & 89 & 1.45 \\
\hline 100 & 12 & 15 & 18 & 22 & 28 & 33 & 41 & 51 & 61 & 67 & 77 & 83 & 93 & 111 & 1.41 \\
\hline 125 & 13 & 16 & 20 & 24 & 30 & 36 & 45 & 56 & 66 & 73 & 84 & 90 & 101 & 121 & 1.39 \\
\hline 175 & 16 & 19 & 23 & 26 & 33 & 38 & 53 & 66 & 78 & 86 & 98 & 107 & 119 & 142 & 1.38 \\
\hline 250 & 18 & 22 & 27 & 34 & 42 & 50 & 62 & 77 & 92 & 101 & 116 & 126 & 140 & 168 & 1.36 \\
\hline 300 & 20 & 25 & 30 & 37 & 46 & 54 & 68 & 85 & 101 & 111 & 126 & 138 & 154 & 184 & 1.35 \\
\hline 400 & 23 & 28 & 34 & 43 & 53 & 63 & 80 & 99 & 118 & 130 & 148 & 162 & 180 & 216 & 1.33 \\
\hline 500 & 27 & 33 & 39 & 49 & 61 & 73 & 91 & 114 & 135 & 148 & 170 & 185 & 206 & 246 & 1.32 \\
\hline 600 & 30 & 37 & 44 & 55 & 68 & 82 & 103 & 128 & 152 & 167 & 191 & 208 & 232 & 277 & 1.31 \\
\hline
\end{tabular}


-From: Facilities Engineering

Phone: 2-3968

Date: October 9, 1979

Subject: BUILDING $306-E$ - STEAM VALVE FAILURE

Ref: 1) Engineering Request No. 1541

2) Nondestructive Test Report 5304

To: D. Gray W/A-50
CC: JA Eaglin
RC Ingersolt
LJ Lucas
LEA/FiTe/LB

$\begin{array}{rlr}C C: & \text { JA Eaglin } & W / A-92 \\ & \text { RC Ingersol1 } & W / C-141 \\ & \text { LJ LuCaS } & W / A-45 \\ & \text { LEA/FiTe/LB } & \end{array}$

Hanford Engineering Development Laboratory

The independent evaluation of the steam valve failure in Building 306-E on August 8, 1979 has been completed. The steam valve failed due to combination of the following factors:

- Valve bonnet was prestressed when valve was overtightened by use of a cheater bar

- By-pass warm-up lines missing at main valves

- System drain valves not used because of relatively inaccessible location and no sewer drain provision

- System isolation valve not used

- Rapid opening of the $6 " \emptyset$ valve outside the building

- Location of the failed valve with respect to the $180^{\circ}$ turn in header

A cursory review of the 300 Area Facilities indicates fifteen additional buildings with potential valve failure problems. Below is a discussion of the steam line installation from the overhead steam grid to the point of valve failure:

The steam line, shown on drawing no. H-3-12785, leaves the overhead grid through a $6^{\prime \prime} \emptyset$ gate valve and slopes down in the direction of steam flow to a point next to the 306 Building wall. (Lack of a by-pass warm-up line on this $6^{n} \emptyset$ valve is a major cause of the steam valve failure.) The steam line tums and runs verticaliy up the exterior wall where it enters the building at a point above the ceiling of an inside corridor. A drip leg equipped with a condensate trap and dra in valve is provided at the bottom of this riser. The drain valve which is intended to drain water from the line on start-up is approximately ten feet above a building entrance walkway and accessible only by ladder. Water discharged from the drain valve sprays the walkway below and anvthing else under it including the operator. Poor accessibility and lack of a sewer drain are the ma.jor reasons this valve is seldom used. Failure to use the drain valve on startup results in one of two. possibilities depending upon the speed of operation of the $6 " \emptyset$ valve upstream at the takeoff from the grid. Slow opening of the $6 " \phi$ valve will permit the temperature and pressure to build up in the line and discharge the water out through the trap. Rapid opening of the valve allows the inrushing steam to propel the condensed water down the pipe and create water hammer in the line. 
From its point of entry into the buil".ng (above the ceiling in the second floor corridor) the steam line turns east and runs the lenqth of the corridor penetrating the firewall between $306-\mathrm{E}$ and $306-11$.

Once through the firewall the line turns and runs north into the High Bay where it turns and runs east for a distance before dropping vertically in a downcomer. The base of the downcomer is a drip leg equipped with a condensate trap and a drain valve. The piping run described above is shown on drawings $\mathrm{H}-3-12834$ and $\mathrm{H}-3-12837$ with an enlarged view of the downcomer shown in Section $\mathrm{H}-\mathrm{H}$ of drawing $\mathrm{H}-3-12831$. During a steam outage, considerable condensate collects at this low point if the 6 " $\emptyset$ valve at the base outlet of the downcomer is closed. If the valve is opened, condensate overflows and collects at the low point downstream. This 6 " $\emptyset$ valve is probably seldom used because of its inaccessible position behind other piping. It appears that the drain valve is seldom if ever used since a pipe plug was installed in the outlet end. The drain valve is also in a "hard-to-work" location and no sewer drain is provided which is probably why it is not used. Difficulty in draining the cold condensate at this point makes start-up a delicate and lengthy operation if water hammer is to be avoided.

The 6" $\emptyset$ valve just off the downcomer is the isolation valve for the 6" $\emptyset$ iine to the Mechanical Equipment Room. This line runs east along the south wall of the High Bay for a distance before turning and rising to the equipment room. At the base of this riser is a drip leg (equipped with a condensate trap and a drain valve) which is the lowest point on the steam line. As mentioned above, during an outage the majority of the condensate collects at this point. The drain valve for this drip leg appeared to be seldon used due to its relatively inaccessible location and lack of a sewer drain. Recently the valve has been put into temporary service by connecting a hose and routing it to the ciosest sewer.

From this last low point the steam line rises and turns to the horizontal, heading south and penetrating the wall into the equipment room. Once through the wall the line enters the branch connection of a $6^{\prime \prime} \emptyset$ tee to form a 6 " $\emptyset$ header running east and west along the north wall of the equipment room. Above this line is a low pressure steam header supplied by the $6^{\prime \prime} \emptyset$ steam line below. In connecting to this low pressure header the $6 " \emptyset$ line makes a $180^{\circ}$ loop on itself, coming out of the loop into a pressure reducing station equipped with gate valves upstream and downstream for isolation. This piping arrangement is shown clearly on drawings $\mathrm{H}-3-12821$ and $\mathrm{H}-3-12822$. It is significant to note that the valve upstream of the pressure reducing station is mounted with the bonnet in the vertical direction. Physical orientation of the valve subjects the bonnet to shock loading.

The series of events preceding the valve failure are discussed below.

The steam service to Building $30 E-[$ was shut down to perform maintenance on the pressure reducing valve in the equipment room. Steam isolation was achieved by closing the $6 " \emptyset$ valve at the takeoff from the overhead steam grid and the 5" $\emptyset$ valve upstream of the pressure reducing valve. It is standard practice to operate these larger valves with an extension to gain leverage (a cheater bar) especially when closing the valve. Since the work to be performed was to remove the pressure reducing valve the $5 " \emptyset$ valve 
was probabiy made extra tight to insure no leakage during work around the open end of the steam pipe. Overtightening the valve to make sure it is closed creates extra stresses (or possibiy results in overstress) in the valve bonnet. Over the life of the valve these cyclic stresses from overtightening the valve can cause cracks to form in the casting. The forces generated by overtightening the valve tend to i ift the bonnet off of the valve body and cause the joint to leak. "The leak is usually compensated for by tightening the bonnet mounting bolts. Since it is not standard practice to use a torque wrench the bonnet. mounting bolts are tightened as required up to the limit of the bolt or the wrenches. overtightening the bolts could cause cracks to form in the flange if the mechanical plus thermal stresses becomehigh enough. In the case of the failed valve it is believed to have been overtightened in the closed position at the time of the failure and appears to have been frequently overtightened in the past. The failure of the valve was the result of water tightened in the past.
hammer created by the quick opening of the $6^{n} \emptyset$ valve outside the building:
The inrushing steam caused the water standing in the low points of the pipe
(Normally the to be propelied down the pipe at relatively high velocity. (Normally the flow of water in a pipe requires thrust restraints at points where flow changes direction to react the forces generated by the inertia of the water.) When the water moving at a relatively high velocity encountered the $180^{\circ}$ loop just.before the closed valve a number of forces were generated creating additional stresses in the valve. The largest of these forces were the impulse force and momentum transfer given to the valve bonnet because of the direction of the force of the flowing water at the top of the $180^{\circ}$ loop. The valve bonnet being in an overstressed condition and being weakened from eariier overstressing failed when subjected to this impact loading.

It is important to remember that if a by-pass warm-up line had been installed and used along with the drains at the low points of the steam line, this incident would not have occurred.

L. E. Anderitini

bet 

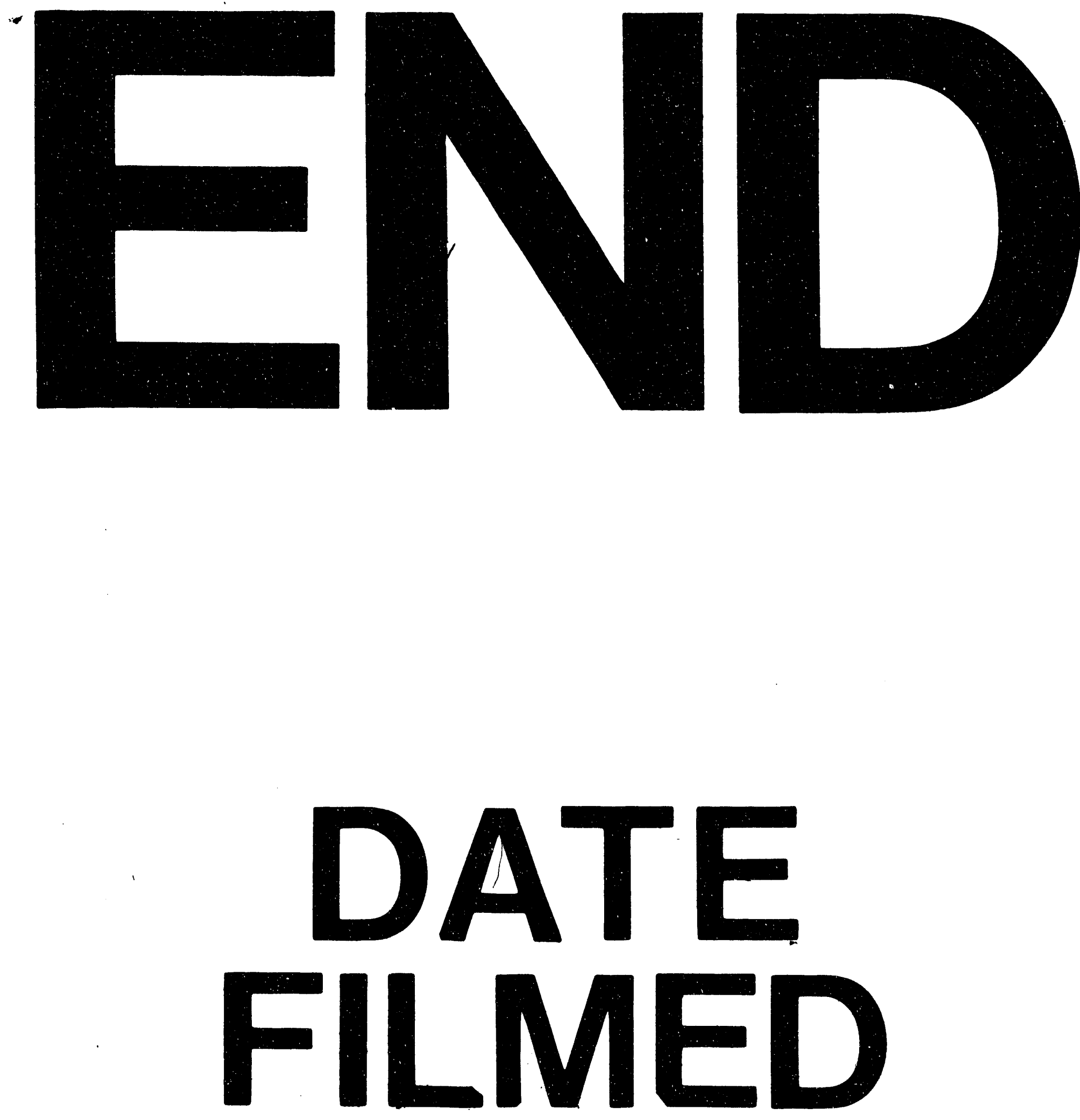

1

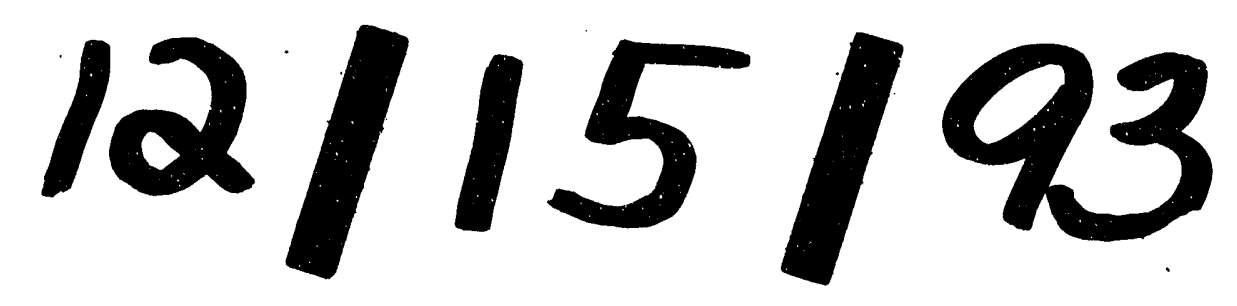


